\title{
CONTRIBUTION TO THE SYSTEMIC MODELING OF PHOTOVOLTAIC DEVICES
}

\author{
Hamza Wertani \\ ENICarthage, Tunisia \\ E-mail: hamzawertani22@gmail.com \\ Jamel Ben Salem \\ ENICarthage, Tunisia \\ E-mail: bsj_jamel@yahoo.fr \\ Mohamed Najeh Lakhoua \\ ENICathage, University of Carthage, Tunisia \\ E-mail: MohamedNajeh.Lakhoua@enicarthage.rnu.tn
}

Submission: 1/7/2021

Accept: 1/8/2021

\section{ABSTRACT}

The modelling of systems using systemic tools has been for a few years, a subject which has attracted the attention of scientists and especially researchers to allow designers to acquire a rigorous approach to problem solving using the capabilities of already existing methods and tools. This document presents a contribution in the field of modelling, where a methodology based on two methods has been proposed. The first concerns the functional analysis to extract the use functions and the constraint parameters from the system. In this methodology, the static functional study is carried out using the SADT method. On the other hand, the dynamic behavioral analysis is carried out by the SA-RT method. Then, we used a behavioral and parametric analysis, the Bond Graph method, to observe the evolution of representative quantities of a photovoltaic system.

Keywords: PV system, SA-RT method, SADT method, MPPT, Bond graph 
DOI: 10.14807/ijmp.v12i8.1544

\section{INTRODUCTION}

The main objective of electricity companies is to provide the amount of electricity demanded by consumers. This does not work without causing problems and challenges as the production will not be adequate to meet the electricity needs and consumption increases over time. In addition, we may be faced with environmental problems such as production conditions, the increase in $\mathrm{CO} 2$ in the world, energy, the difficulty of storing large quantities of electricity quickly, easily and economically.

In this context, photovoltaic energy is considered to be one of the promising energies. To overcome the problems linked to solar panel yields and obtain the maximum energy, it is essential to find solutions for optimizing photovoltaic systems. In addition, it is necessary to enhance the circuits adapting these sources to their loads. An MPPT (maximum power point tracking) controller is a device that allows the maximum possible energy to be extracted, taking into account climatic variations (brightness and temperature) (Rekioua, 2013).

Since 1968 (year of the first publication of the first control law in MPPT mode (Boehinger et al., 1968), researchers have developed several optimization techniques. Analog methods are often simple to perform and inexpensive. Among these, we recall the servo-control technique of the generator output voltage, the "blind" search for maximum power by incrementing the duty cycle of the chopper known as the power gradient and the modulation by synchronous detection.

The overall, the objective of the paper is to propose a methodology different from analogy methods which is the systemic modelling, this methodology allows the design or the analysis of a complex system from tools and methods (Lakhoua, 2020).

In what follows, we will present the different parts of the studied system which is the photovoltaic system. Then we will propose the methodology which is based on the hybridization and the cascading of two methods for the three levels of analysis. The first level of analysis is the functional analysis of the photovoltaic system. This level applies the SADT methodology to put the system in its environment. The study of the environment results in the extraction of the technical functions of the system and the stress parameters as well; that are the mechanisms responsible for performing the functions (Ahmed et al., 2014).

The second level is the analysis of the functioning of the system in real time. It is based on the SA-RT methodology, in order to model the development and the operating sequences of the mechatronic system. Then using diagrams of the method, the circulation of internal and external information of the system is presented. Then, a sequential study allows appearing the 
DOI: 10.14807/ijmp.v12i8.1544

transitions and the data responsible for the transition from one operating state to another. The third level of analysis is based on the Bond Graph tool to find an electrical modelling of the photovoltaic system technical functions (Jha et al., 2016).

\section{PHOTOVOLTAIC PANEL MODELLING}

A photovoltaic panel consists of several modules connected in series and in parallel to obtain the desired voltages and power. Every module is collected of numerous PV cells in parallel and in series. A comparison made in between the two-diode model and the one-diode model under the same conditions, shows that the series resistance marks the difference between the different models. In fact, the one-diode model combines simplicity, precision and presents the choice that is considered the most interesting. Figure 1 displays the electrical model of the PV cell, described by the current $I_{p h}$, depending on the photovoltaic irradiation in parallel with a diode and the shunt resistor $R_{s h}$, the entire components are mounted in series with the resistance $R_{S}$ (Allani, 2019).

With:

$$
I=I_{p h}-I_{D}
$$

$I$ : The output current of the Photovoltaic Generator

$I_{p h}$ : The photocurrent of the solar Panel

$I_{D}$ : The diode current of the solar Panel

$I_{D}=I_{0} \cdot\left[\exp \left(\frac{q \cdot V_{p v}}{a k T}\right)-1\right]$

With:

$I_{0}$ : The photovoltaic reserve saturation current diode

$a$ : The ideality factor

$K$ : The Botzman Constant

$I_{L}=\left[I_{S C}+K_{I} \cdot\left(T-T_{r e f}\right)\right] \frac{\mathrm{G}}{G_{r e f}}$

With:

$K_{I}$ : The temperature coefficient in current

$T$ : The temperature

$T_{\text {ref }}$ : The reference Temperature

$G$ : The irradiance

$G_{r e f}$ : The reference irradiance

$I_{0}=I_{o s}\left(\frac{\mathrm{T}}{T_{r e f}}\right)^{\frac{3}{a}} \cdot \exp \left[\left(\frac{q \cdot E_{g a p}}{a k T}\right)\left(\frac{1}{T_{r e f}}-\frac{1}{T}\right)\right]$

With:

$q$ : The elementary charge in Coulomb

$E_{\text {gap }}$ : The Gap energy. 
DOI: 10.14807/ijmp.v12i8.1544

$$
\begin{aligned}
& I_{0}=\frac{I_{S C}}{\left.\exp \left(\frac{q \cdot V_{o c}}{a k T_{r e f}}\right)-1\right)} \\
& I=I_{p h}-I_{0} \cdot\left[\exp \left(\frac{q \cdot\left(V_{p v}+I_{p v} \cdot r_{S}\right.}{a k T}\right)-1\right]-\left(\frac{V_{p v}+I_{p v} \cdot r_{s}}{R_{S h}}\right) \\
& \hline \overbrace{V_{p}}^{I_{D}}
\end{aligned}
$$



Figure 1: Complete physical-mathematical PV array model

\section{RESEARCH METHOD}

\subsection{SADT method}

The SADT method gives a systemic approach based on the structuring of activities and technical data, after having transformed a complex system into a set of simple interacting systems (Schoman \& Ross, 1977). The SADT method is a hierarchical and top-down analysis method which appeared in 1977 by Douglas T. Ross within the company SOFTTECH (U.S.A.) (Ward, 1986). It is a method of analysis by successive levels of descriptive approach of a set or a system (Benard, 2008).

The SADT method is based on an easy to learn graphic and textual formalism. It allows on the one hand to model the multidisciplinary problem posed and to ensure effective communication between the various stakeholders concerned by the system to be analyzed. On the other hand, to seek to extract a solution to the problems posed. We can apply the SADT method to the management of a business as well as to an automated system, so is essentially a method of structured representation of a system formed of activities "anything that contributes to the provision of added value to data » and data are all the technical data of the company (economic, technological, physical, ...) (Lakhoua et al., 2016).

The construction of a SADT model begins with the most general and abstract description of the system. This description, contained in a single module, can be broken down into sub-modules; each representing a component of the initial box. This process can then be iterated until the desired level of detail is obtained. Each of the sub-modules or child modules must not add or subtract anything from the context of the parent module (Lakhoua et al, 2009). This breakdown is illustrated in Figure 2 and corresponds to a top-down analysis of the system. 


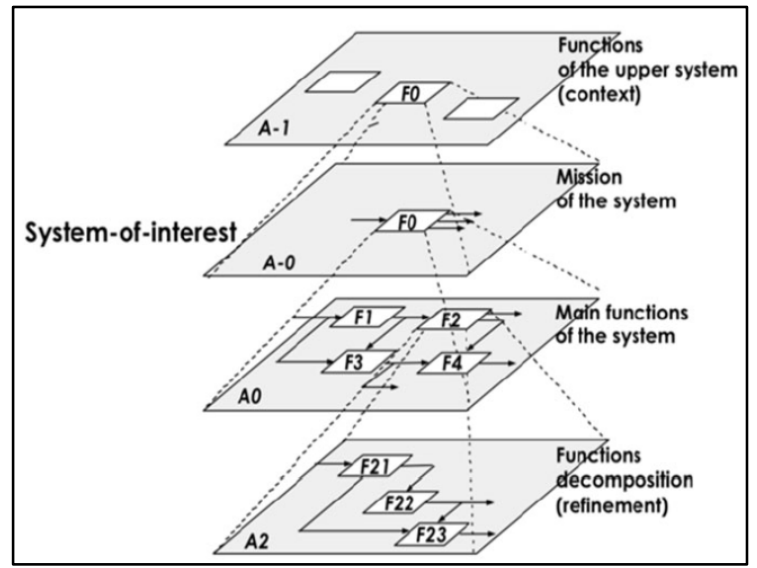

Figure 2: Structure of an SADT model Source: Lakhoua et al. (2020)

The analysis method does not provide any information on potential failures that a system may encounter. For this reason, it is necessary to study methods for determining and evaluating failures as well as to specify the different states of the cereal system (Marca, 2006 and Ben Jouida, 2008).

\subsection{SA-RT method}

SA-RT (Structured Analysis and Real Time) is a method of functional and operational analysis of computer systems specification. It takes into account the dynamic aspect of the system analyzed. This method provides a graphical and textual description of the application or system in terms of need. SA-RT is an extension of the SA method (Structured Analysis or Structured Analysis proposed by Tom Demarco in 1978) which has been widely used. There are two variations of SA-RT, one by Ward and Mellor in 1986, the other by Hatley and Pirbhai in 1987 (Glaa et al., 2016; Renaux, 2013).

The SA / RT method considers the specification of real-time systems from three points of view (Flo, 1992):

- Functional: representation of the transformation that the system operates on the data and specification of the processes that transform the data.

- Dynamics: representation of the events that condition the evolution of a system and specification of the control logic that produces actions and events based on the input event and changes the state system.

- Informational: defines the data handled by the functions.

The Context diagram is an extremely important first step since it will define the context and the external environment of the piloted system. We can consider it as the production 
DOI: 10.14807/ijmp.v12i8.1544

contract between the designer and his client. Model edges or terminations will only appear in this diagram. The precise descriptions of these endings, as well as data or possibly incoming or outgoing events thereof, are the responsibility of the originator (Demri, 2010; Khanh, 2008).

The first level of analysis is represented by the preliminary diagram. This preliminary diagram is the first breakdown of the process to be performed presented in the context diagram. At this level, the diagram represents the "graphic" list of the functional processes necessary to the application without worrying about the sequence. The number of functional processes making up this preliminary diagram must be limited in order to have better readability: 5 to 9 maximum (Lakhoua, 2011).

The diagram in Figure 3 below presents the general organization of the SA-RT method with the sequence of the different stages and all the documents produced (Ben Salem et al., 2016).

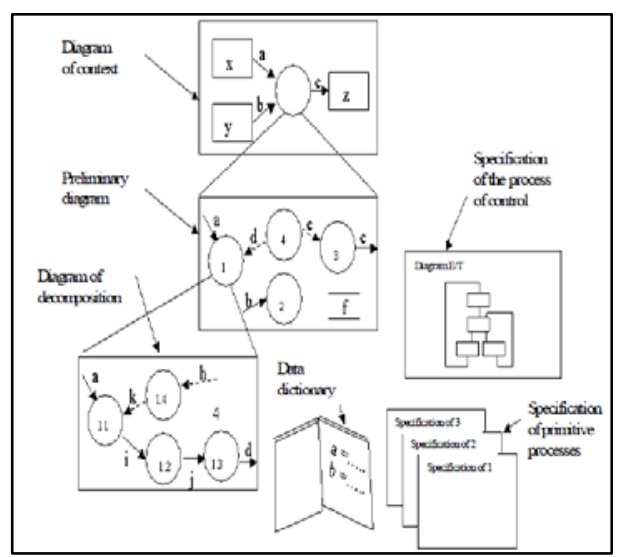

Figure 3: Organization of the SA-RT model

Source: Lakhoua et al. (2020)

\subsection{Bond graphs}

\subsubsection{Bond Graph formalism}

The bond graph formalism was introduced by H. Paynter in 1961 and formalized by Karnopp and Rosenberg in 1975. This methodology entered Europe at the end of the 1970s through the Netherlands (University of Twente) and France (company Alstom) (Ben Jouida, 2008; Khaouch et al., 2017). The bond graph tool is now used regularly in a few companies, particularly in the automotive industry (PSA, Renault, Ford, Toyota, General Motors, etc.) (Cheng, 2016). 
DOI: 10.14807/ijmp.v12i8.1544

Table 1: Bond graph and applications

\begin{tabular}{|c|l|}
\hline Application & \multicolumn{1}{|l|}{ advantages } \\
\hline \multirow{3}{*}{ Modeling } & $\begin{array}{l}\text { Makes possible the energetic study } \\
\text { Makes simpler the building of models for multi-disciplinary } \\
\text { systems } \\
\text { Leads to a systematic writing of mathematical models (linear or } \\
\text { nonlinear associated }\end{array}$ \\
\hline \multirow{2}{*}{ Analysis } & $\begin{array}{l}\text { Estimation of the dynamic of the model and identification of the } \\
\text { slow and fast variables } \\
\text { Study of structural properties }\end{array}$ \\
\hline \multirow{2}{*}{ Identification } & $\begin{array}{l}\text { Possibility to build a state observer from the model } \\
\text { Design of control laws from simplified models }\end{array}$ \\
\hline Monitoring & $\begin{array}{l}\text { No "black box" model } \\
\text { Identification of unknown parameters, but knowledge of the } \\
\text { associated physical phenomena }\end{array}$ \\
\hline \multirow{2}{*}{ Simulation } & $\begin{array}{l}\text { Graphical determination of the "monitorability" conditions and of } \\
\text { the number and location of sensors to make the faults localizable } \\
\text { and detectable }\end{array}$ \\
\hline $\begin{array}{l}\text { Specific software (CAMP+ASCL, ARCHER, 20 SIM) } \\
\text { A knowledge of the numerical problems which may happen } \\
\text { (algebraic-differential equation, implicit equation) by the means } \\
\text { of causality }\end{array}$ \\
\hline
\end{tabular}

That method illustrates the energy transfers in the system using power links. A power link is symbolized by a half-arrow, the orientation of which indicates the direction of power transfer (Ben Salem et al, 2016). Thus, Figure 4 represents the transfer of power from subsystem A to subsystem B.



Figure 4: Bond graph: transfert de puissance de A vers B

One of the fundamental characteristics of bond graph formalism is its unifying aspect, whatever the physical field of application (electrical, mechanical, hydraulic, chemical, etc.). We can visualize the energy transfer in multi domain systems thanks to the generalized variables presented in the following paragraph (Ould Bouamama \& Thoma, 2000).

\subsubsection{Generalized variables}

Each power link carries two pieces of information simultaneously: effort e and flow $\mathrm{f}$. These are the generalized power variables (their product being the transferred power). We also use generalized energy variables: the moment $\mathrm{p}$ (the integral of the effort with respect to time) and the displacement q (the integral of the flux with respect to time) (Demri et al., 2008).

\subsubsection{Bond graph elements}

We use elements to represent phenomena that link generalized variables. We can separate them into three categories: 
DOI: 10.14807/ijmp.v12i8.1544

$>$ Actifs Elements

The active elements are sources of effort or flow. These may have one value independent of any external influence (for example gravity) symbolized by Se for sources of force or Sf for sources of flux, or modulated according to a signal (symbolized by MSe or MSf). These elements provide power (positive or negative) to the system. Consequently, the direction of the half-arrow leaving the element is compulsory (Faucher, 2004).

\section{Passifs elements}

The Paynter's tetrahedron presented in Figure 5 illustrates the relationships between generalized variables passing through passive elements (R, I, C). These can be of linear or nonlinear characteristics. In this section, we are only talking about passive elements with a single incoming power link. We call them single-port passive items.



Figure 5: Tetrahedron of state

The element $\mathrm{R}$ is dissipative of energy, in the form of heat. Elements I and $\mathrm{C}$ are the energy storage elements. The passive elements consume power and transform it either into energy dissipated as heat in the elements R, or into energy stored in the elements I (kinetic energy) and C (potential energy). The orientation of the half-arrow is therefore incoming towards the element.

\section{$>$ Junctions and detectors}

The junctions are used to couple the elements previously presented. These are conservative of power. Four types of junction are defined. These are the 0,1 , TF (transformer) and GY (gyrator) junctions.

- The junctions 1 are iso-flux junctions

- The 0 junctions are iso-effort junctions

- The TF junctions transform the effort - effort, flow - flow variables.

- The GY junctions transform the effort - flow, flow - effort variables. 
DOI: 10.14807/ijmp.v12i8.1544

Let's use the force (De) and flow (Df) detectors to measure the corresponding variables in a bond graph model. We consider them ideal: they do not consume power; we therefore use a signal type link (an arrow) (Plateaux et al., 2009; Diagne, 2015).

\section{HYBRIDIZATION OF TOOLS AND METHODS}

Researchers, Lakhoua et al. (2016), presented the need for the structured analysis and the modelling of control-command applications in a thermal power plant (TPP) using a supervisory control and data acquisition system (SCADA). Then, the architecture of a SCADA system in a TPP is presented. A significant example of a control-command application in a TPP in Tunisia is presented. It is concerning the water-steam cycle of the TPP which is composed of two stations: the inverse osmosis station and the demineralization station. In fact, an application of the analysis and the modelling methods in a TPP, generally used in industry, on the basis of the Grafcet and SA-RT formalism is presented. In fact, different modules are represented and described: Context Diagram, Data Flows Diagram, Control Flows Diagram, State Transition Diagram, Timing Specifications and Requirements Dictionary. Finally, this functional and operational analysis allows us to help the different steps of the specification, the programming and the configuration of a new tabular in a SCADA system.

Researchers, Demri et al. (2008), proposed using several methods (SADT, AMDEC, and MOPs) to study the reliability of a mechatronic system. The study begins with a functional analysis using the SADT method to define the hardware limits, the various operations and functions performed by the system and these different configurations. They noted that there was insufficient information on the modes and effects of failure. For this they proposed to use MOP and AMDEC (Failure Modes, Effects and Criticality Analysis, AMDEC is a tool used in the quality approach and in the framework of dependability consists in analyzing failures, their causes, their effects (Fritzson, 1998) to complete the dysfunctional analysis of a complex system.

Researchers, Plateaux et al. (2009), proposed to integrate the entire part of the V-design cycle (The V-cycle model is a conceptual model of project management produced following the reactivity problem of the cascade model. The $\mathrm{V}$ cycle is made up of 9 stages, it is divided into 3 parts: on the left part of the $\mathrm{V}$ the design phase, on the tip of the $\mathrm{V}$ the realization and on the right part of the $\mathrm{V}$, the test phase) in order to achieve continuity of modelling through the different levels of approach and design (requirements, functional, components and structural). They have proposed a hybrid method based on several tools and methods such as SADT, 
DOI: 10.14807/ijmp.v12i8.1544

SysML, and Modelica (Modelica is an object oriented modeling language that allows practical textual modelling to simulate the behaviour of complex and multidisciplinary systems (Dumola, 2004)) in the Dymola environment

Researchers, Turki and Sghaier (2005) presented a methodology for the design of mechatronic systems, they used SysML to support the analysis, design, verification and validation phase of the models. Then, they used the activity diagrams to express the Bond Graphs model. They concluded that SysML users can easily integrate the bond graph into their proposed design. These studies are based on the improvement of the UML 2.0 language in order to find the SysML profile mapping the Bond Graph formalism which is a useful tool when it comes to mechatronic systems. They established a correspondence between the graphic elements of connection and these extensions.

Researchers Salah et al. (2014) discussed the advantage of using methods for operational safety studies and the analysis of control systems. Therefore, they present the different concepts of operational safety of industrial installations. Their contribution is to locate the main methods used in operational safety studies on the procedures used for the analysis and design of control-command systems for searching a hybridization of these methods. In fact, they study on the one hand the SADT, FMDS and Safe-SADT methods and on the other hand the extended SADT and SA / RT methods.

\section{RESULTS AND DISCUSSION}

\subsection{SADT method}

Figure 6 shows the A-0 flowchart of the SADT method. This actigram makes it possible to highlight all the information relating to the system such as input work material (solar energy), output work material (electrical energy), control data (failures and Defects Detector, MPPT, User) and the elements responsible for carrying out the global function (PV fields, PV Modules and Cells, Inverters, DC Cables, AC Cables). This actigram presents the overall function inside a box (Convert solar energy into electrical energy).

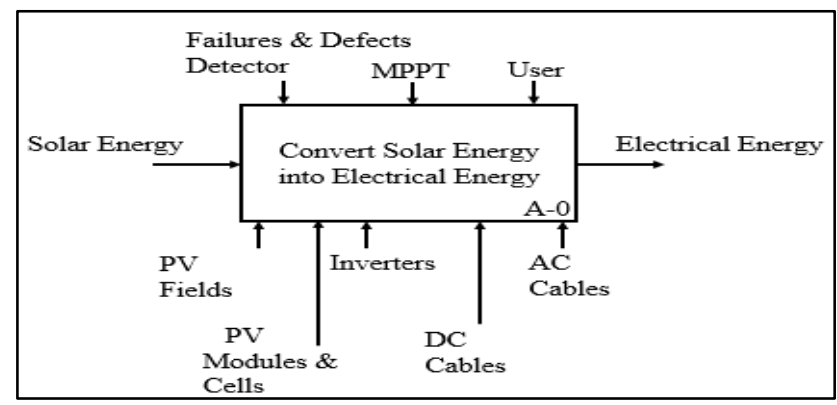

Figure 6: Node A-0 Actigram 
DOI: 10.14807/ijmp.v12i8.1544

The second diagram of A0 level illustrated in Figure 7 is a breakdown of the previous A-0 level, it contains 5 boxes that represent all of the activities grouped together to ensure the service function offered by the system.

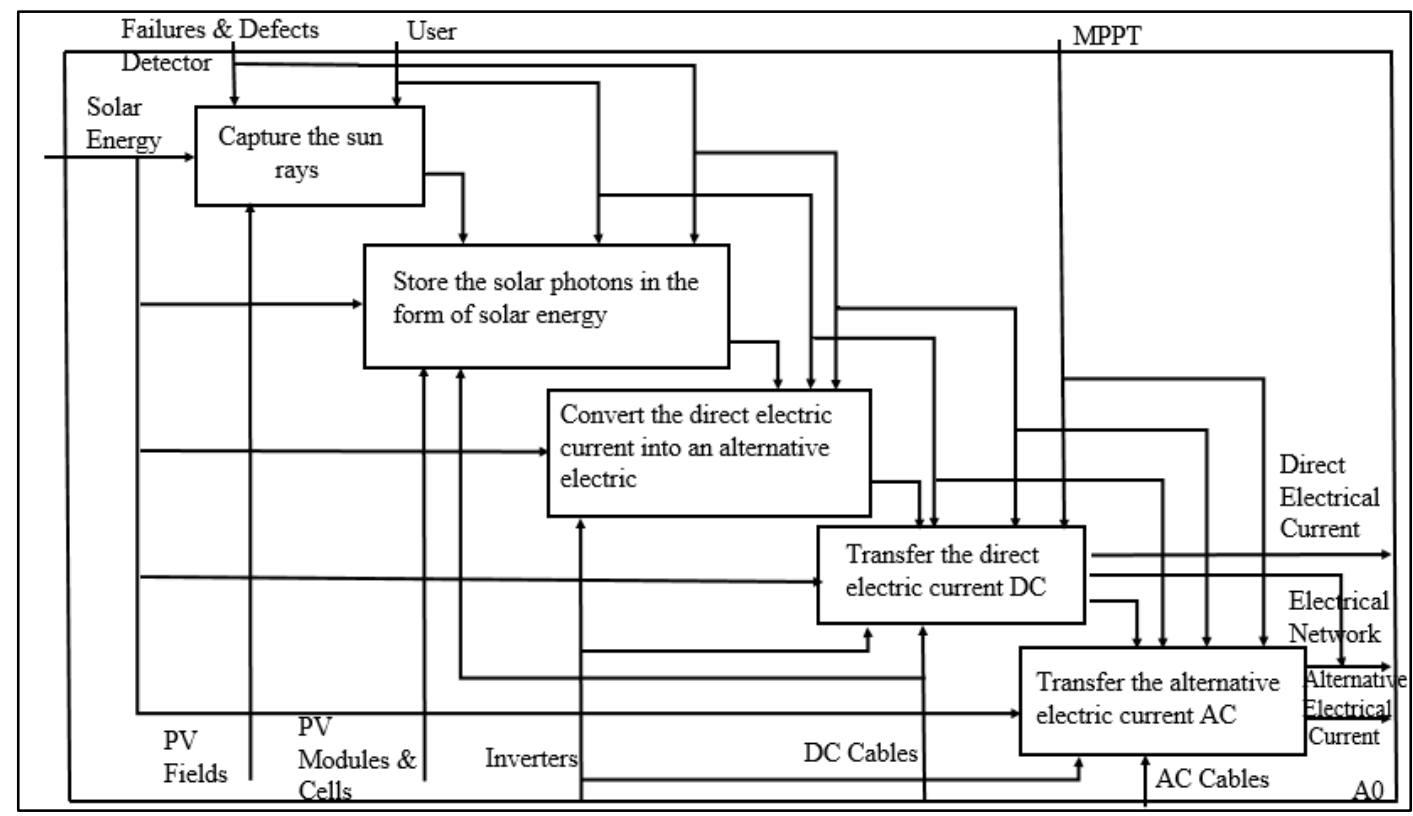

Figure 7: Node A0 of a PV system

The result of the analysis by SADT of the photovoltaic system supervision allowed us to identify using diagrams, in addition to the activities of the system studied, four categories of parameters (inputs, outputs, constraints and mechanisms) according to a hierarchical and topdown approach.

\subsection{SA-RT method}

This part presents a modeling of a photovoltaic system based on the SA-RT Cartesian analysis method to achieve a functional and operational hierarchical decomposition. Indeed, the environmental modeling and the behavioral modeling of the photovoltaic system are well detailed.

\subsubsection{Modelisation of environment}

The first phase of analysis consists of developing the environment modeling, more precisely the application data context diagram and the list of events. 
DOI: 10.14807/ijmp.v12i8.1544

\section{Data context diagram}

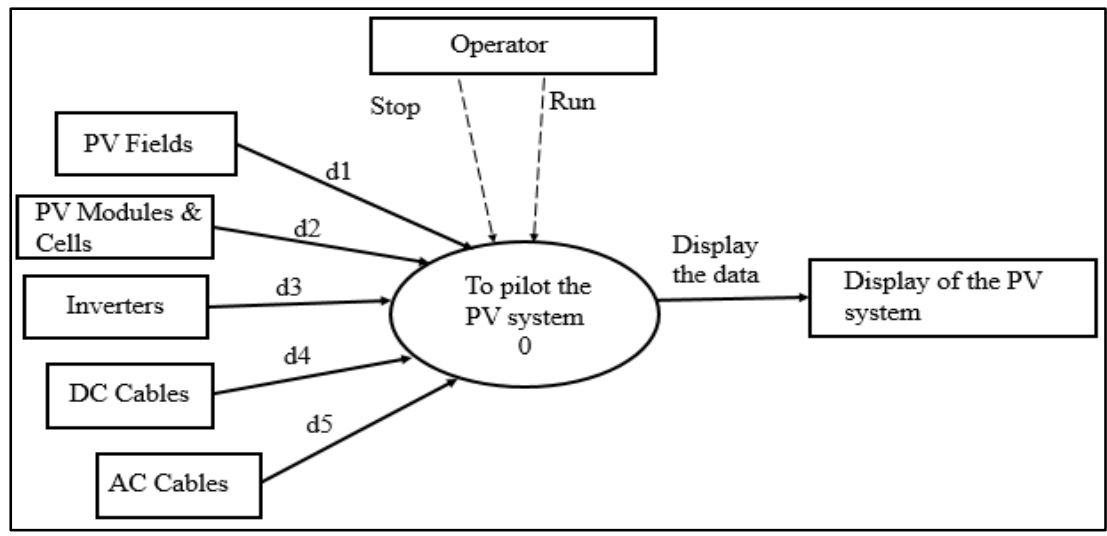

Figure 8: Context Diagram of the PV system

Figure 8 presents the DC of a photovoltaic system which integrates the initial main process 0 "supervise the photovoltaic system" which constitutes the application of controlcommand to study, the 7 borts of models corresponding to 5 inputs and only one output and one edge corresponds to the operator console. In addition, we have 2 events which are "on" and "off”.

\subsubsection{Behavioral modeling}

The Behavioral modeling is the second analysis step which consists in developing in particular the data flow diagram, the control flow diagram and the transition state diagram.

\section{Control flow diagram}

The control flow diagram (DFC), presented in Figure 9 presents a functional analysis or decomposition of the initial main process to have the seven functional processes of the data flow diagram and a control process. It therefore represents the additional step in the data flow diagram (DFD). In fact, the seven basic functional processes identified are: acquiring the signals; convert A / N signals; Acquire the irradiation data; Transform solar radiation into electricity; Identify the operating mode of the photovoltaic panels; Present the photovoltaic applications; Study the photovoltaic design factors; Use the voltage regulation according to the load; Monitor the photovoltaic installation. 
DOI: 10.14807/ijmp.v12i8.1544



Figure 9: Control Flow Diagram of the PV system

E / D events are used together to drive an endless loop process. In our case, Acquire the data of the radiation; Transform solar radiation; Identify the operating mode; Present the photovoltaic applications; Study the design factors; Use the voltage regulation according to the load; Monitor the photovoltaic system.

The control process aims to express the execution or the sequence of the seven basic functional processes. The objective is not completely achieved by the flow control diagram. It is therefore necessary to add additional information describing the operation of the control process, this generally results in the state / transition diagram (DET).

\section{Transition state diagram}

The transition state diagram presented in Figure 10 is used to describe or specify the control process. In other words, the state / transition diagram explains the dynamic behavior of the control-command application.

The state / transition diagram is made up of four elements: current state; event; action; next state. It clearly describes the different states as well as the events - actions of an application for supervising a control system - command. 


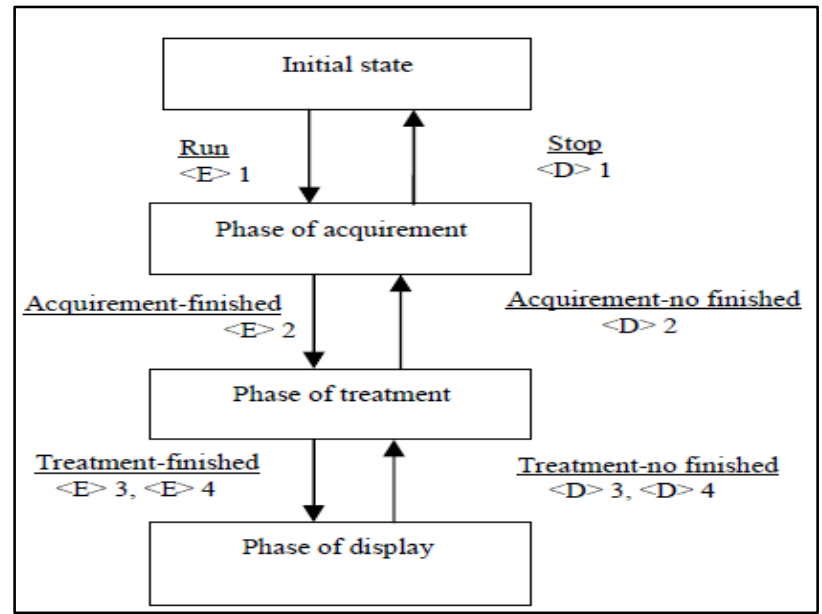

Figure 10: State - Transition diagram of the PV system

\subsection{Bond graph}

The behavior of the ideal photovoltaic cell during darkness resembles a diode because the cell is not an active slide, it does not produce current or voltage. However, if it is connected to an external source (high voltage) it produces a current ID called current of the diode. The ideal circuit does not take into account the resistances in series Rs and parallel Rsh which characterizes a real photovoltaic module. Figure 1 shows the equivalent circuit of a photovoltaic cell.

We first consider the ideal cell model that does not involve resistance. The basic electrical parameters of a solar cell are:

- Short circuit current icc. This is the largest value of the current generated by the cell. It occurs in short circuit condition. So, considering that the photo-current iph is equal to the short-circuit current we have: icc $=$ iph.

- Open circuit voltage vp. It is the second most important value of a solar cell. It corresponds to the drop in voltage in the no-load diode, i.e. the intersection of the V-I curve with the axis of the voltage.

- Maximum cell power obtained by an MPPT algorithm explained below. In terms of the bond graph methodology, the electric model of the ideal photovoltaic cell shown in Figure 1, is shown as in Figure 11. 




Figure 11: Bond graph model of the photovoltaic cell

The representation of the diode is made using a nonlinear resistance Rd, the currentvoltage relationship is a non-linear function. The same model was presented in (Andoulsi et al., 2002; Mezghanni et al., 2007). A more general model is obtained by adding the resistors Rs and Rsh, which respectively model the voltage drops due to the connections and the leakage currents due to the imperfections of the material used for the construction of the cell. Adding the resistors has a direct impact on the characteristic responses of the solar cell (which depends on the numerical value of the resistors).

Usually, the parallel resistance is taken with a large value and the series resistance with a small value, they are neglected.

Adding resistors, however, poses problems of resolution and computation time due to the possible double choice of causality and the algebraic loop which exists between resistors. This problem was presented in details in (Andoulsi, 2001), and also explained in (Roboam, 2007). In the first reference the problem was solved with the use of the ideal model by considering the capacity that exists in the region of depletion and in the diffusion of carriers, depending on the light and temperature at the cell level. In the second reference, the series resistance has been neglected.

The bond graph in Figure 11 was taken from (Mezghanni et al., 2007). It contains a capacitive element used to initialize the model, the element noted Rd corresponds to the resistance of the diode and it contains the nonlinear characteristic. For a given temperature and a given illumination, the current / voltage characteristic curve of the photovoltaic cell is given in Figure 12, which corresponds to a photovoltaic cell of a Kaneka G-SA060 panel. 
ISSN: 2236-269X

DOI: 10.14807/ijmp.v12i8.1544

Table 2: Kaneka G-SA060 values (at standard test conditions: $1000 \mathrm{~W} / \mathrm{m}^{\wedge} 2 \& 25^{\circ} \mathrm{C}$ )

\begin{tabular}{|l|l|}
\hline Parameters of PV & Values and units \\
\hline Pmax(W) & $60.3 \mathrm{~W}$ \\
\hline Cells per Module & 61 \\
\hline Vpv at Pmax(V) & $67 \mathrm{~V}$ \\
\hline Ipv at Pmax(A) & $0.9 \mathrm{~A}$ \\
\hline Vo (Open Circuit Voltage) (V) & $91.8 \mathrm{~V}$ \\
\hline Is(Short Circuit Current)(A) & $1.19 \mathrm{~A}$ \\
\hline a & 2.1922 \\
\hline Rs(Series Resistance)(ohm) & 5.8 ohms \\
\hline Rsh(Shunt Resistance)(ohm) & 254.8 ohms \\
\hline
\end{tabular}

In order to characterize the solar cell, we used the model presented to provide the values of the tension $\mathrm{V}$, of the current I and of the generated power produces $\mathrm{P}$.

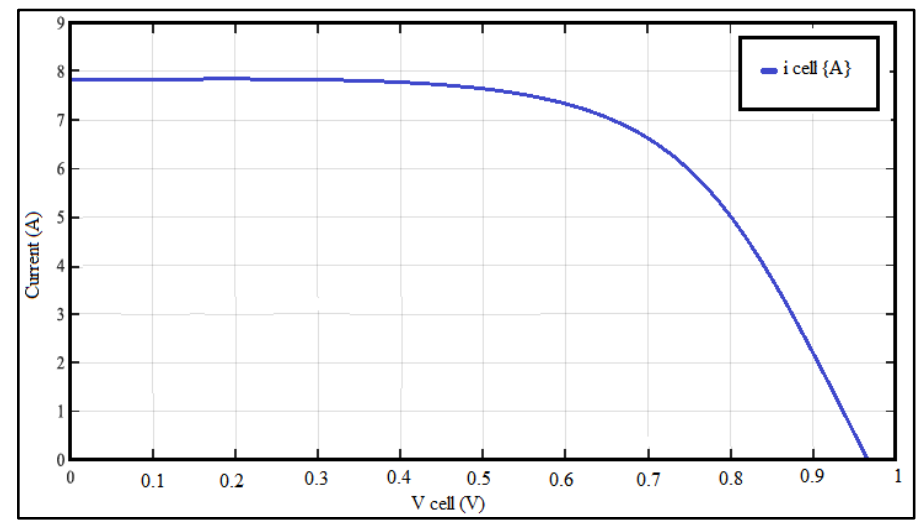

Figure 12: Current / voltage characteristic of a photovoltaic cell

Figures 13, 14 and 15 show the current / voltage and power / voltage curves of the Kaneka G-SA060 panel for different temperature values (Figure 14 and 15) $\mathrm{T}=10^{\circ}, 25^{\circ}, 35$ $\circ, 50^{\circ} \mathrm{C}$ with lighting fixed $1000 \mathrm{~W} / \mathrm{m} 2$, and for different lighting values (Figure 13) $\mathrm{G}=1 \mathrm{k}$, $800,600,400 \mathrm{~W} / \mathrm{m} 2$ with a fixed temperature of $25^{\circ}$.

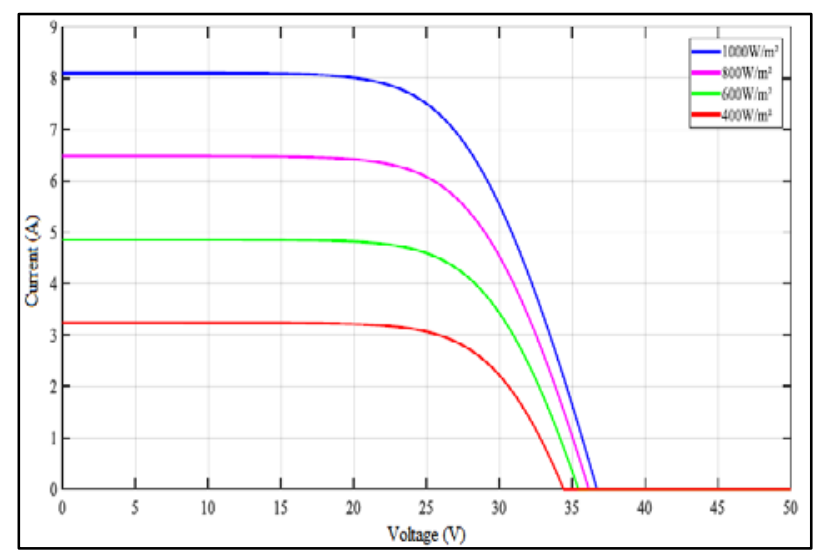

Figure 13: Characteristics I-V with the variation of solar irradiation 


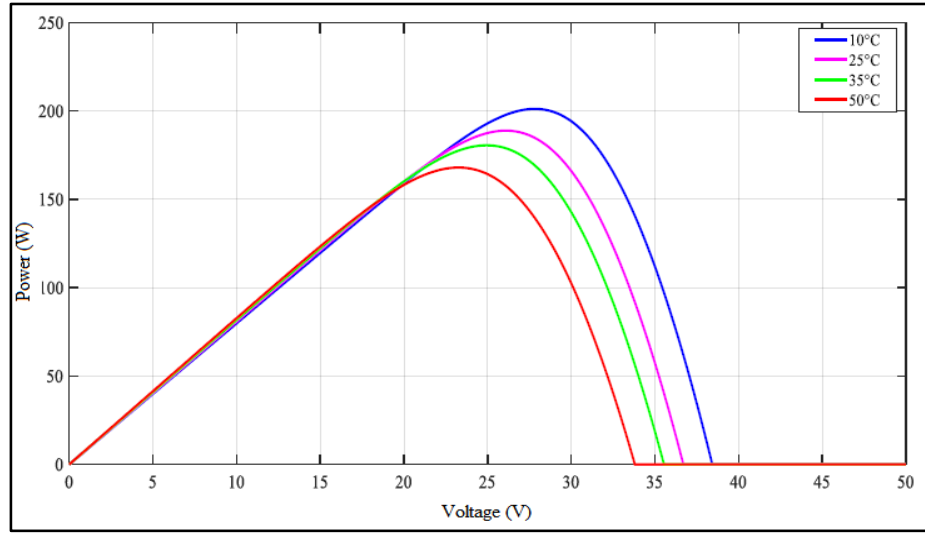

Figure 14: Characteristic P-V with the temperature variation

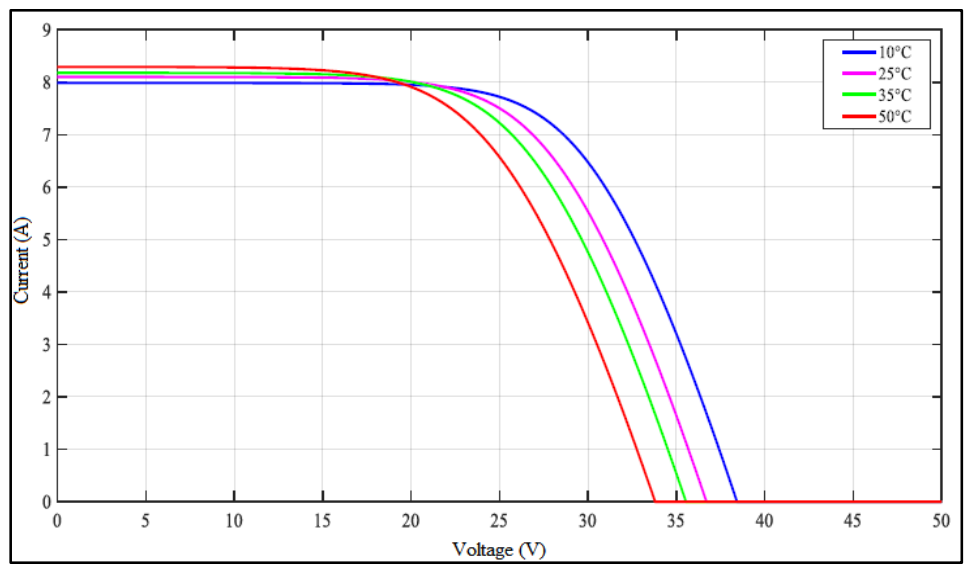

Figure 15: Characteristics I-V with the temperature variation

\section{STUDY ON METHODS OF ANALYSIS}

To assess the three systemic methods (SADT, SA-RT and Bond graph) presented previously for the purpose of carrying out a comparative study, the deductions collected are summarized in the following table (Table 3) (Wertani et al., 2020).

Table 3: Comparative study on methods of analysis

\begin{tabular}{|c|c|c|c|}
\hline Method/ tools & SADT & SA-RT & Bond graph \\
\hline $\begin{array}{l}\text { Functional } \\
\text { modeling }\end{array}$ & $\begin{array}{l}\text { Very strong in functional } \\
\text { modeling, can be } \\
\text { achieved using actigrams } \\
\text { and datagrams. }\end{array}$ & $\begin{array}{l}\text { Very strong for the functional } \\
\text { and dynamic modeling of the } \\
\text { system. }\end{array}$ & $\begin{array}{l}\text { Does not allow a functional } \\
\text { analysis because the } \\
\text { environment of the system } \\
\text { does not appear on the models. }\end{array}$ \\
\hline $\begin{array}{l}\text { Structural } \\
\text { modeling }\end{array}$ & $\begin{array}{l}\text { Can be performed by } \\
\text { indicating mechanisms } \\
\text { and sometimes by } \\
\text { datagrams. }\end{array}$ & $\begin{array}{l}\text { Object oriented method allows } \\
\text { structural modeling. }\end{array}$ & $\begin{array}{l}\text { Difficult to achieve because } \\
\text { there are elements that cannot } \\
\text { be modeled by the elements of } \\
\text { the bond graph. }\end{array}$ \\
\hline $\begin{array}{l}\text { Parametric } \\
\text { modeling }\end{array}$ & $\begin{array}{l}\text { Can be } \\
\text { superficially } \\
\text { indication. }\end{array}$ & $\begin{array}{l}\text { Parametric representation is } \\
\text { possible but cannot be modeled } \\
\text { due to insufficient information } \\
\text { presented by this } \\
\text { representation }\end{array}$ & $\begin{array}{l}\text { Can be performed if the system } \\
\text { is well known and for physical } \\
\text { and non-informational } \\
\text { parameters. }\end{array}$ \\
\hline $\begin{array}{l}\text { Behavioral } \\
\text { modeling }\end{array}$ & $\begin{array}{l}\text { Can be performed by } \\
\text { indicating some possible } \\
\text { sequencing and } \\
\text { identification } \\
\text { mechanisms. }\end{array}$ & $\begin{array}{l}\text { The behavior of the parameters } \\
\text { cannot be modeled by the SA- } \\
\text { RT method without using } \\
\text { another method. }\end{array}$ & $\begin{array}{l}\text { This modeling can be carried } \\
\text { out to model the behaviors of } \\
\text { the physical elements. }\end{array}$ \\
\hline
\end{tabular}


DOI: 10.14807/ijmp.v12i8.1544

Table 3 presents the approach of the analysis which we propose which is a hybrid approach, making cooperate different methods and making it possible to cover the principal functions of an industrial system particularly the control-command systems.

An integral modelling of such a system is that which makes it possible to translate the two aspects of the system, studied in this research work in their details. These two aspects are dependability and control. Of course, building this type of modelling is a difficult process; and even if we manage to achieve it, the exploitation of the built model would remain dependent on the objectives expected from the study.

This is how the three levels of analysis SADT, SA-RT and Bond graph, which are based on different graphic and textual formalisms, can cover the two aspects studied on the one hand, and offer a communication support between the various users of the system, on the other hand. In this perspective, the use of the SADT method makes it possible to complete the observation of the system carried out and to specify the relationships between the activities and the data of the system as well as the parameters exchanged.

The use of the SA-RT method has models leading to a detailed functional analysis. Apart from this, parametric and behavioral modelling seem insufficient by this of the Bond graph method makes it possible to control the internal and external parameters of the system. Indeed, any change in these parameters can be simulated after modifying the values of the passive elements that constitute the model, thus seeing its effects on the evolution of the outputs.

\section{CONCLUSIONS}

In this paper, we have presented a contribution in the field of a photovoltaic system modelling, in which a methodology based on two methods has been proposed. The first is concerned with functional analysis to extract usage functions and stress parameters from the system studied. In this methodology, the static functional study is carried out using the SADT method. On the other hand, the dynamic behavioral analysis is made by the SA-RT method.

Then, a behavioral and parametric analysis, which we used the Bond Graph method to observe the evolution of the quantities representative of the system. This is how we also carried out a comparative study of these two methods based on several analytical views. This study allowed us to choose the basis of our methodology that we will follow in our contribution. This methodology is based on the hybridization and cascading of a set of methods which seems to us more efficient for the modelling of a photovoltaic system. 
DOI: 10.14807/ijmp.v12i8.1544

This work can be improved on two levels: at the level of modelling, it is useful to find a hybrid methodology allowing to pass from one method to another, at this moment we reduce the set of models proposed by this modelling. At the observation level by inserting parameters supervision logarithms after having simulated the system in breast mode then in degraded mode.

This photovoltaic system is used as an electrical system which makes the targeted contributions by this article may be used for other more complex systems in futures work

\section{REFERENCES}

Ahmed, F., Robinson, S., \& Tako, A. A. (2014). Using the structred analysis and design technique (SADT) in simulation conceptual modeling, Simulation Conference (WSC). 1038-1049.

Allani, M. Y., Tadeo, F., Mezghanni, D., \& Mami, A. (2019). Application of system modeling and simulation of the photovoltaic production, IJCSNS International Journal of Computer Science and Network, 19(5).

Andoulsi, R. (2001). Etude d'une Classe de Systèmes Photovoltaïques Par une Approche Bond Graph Modélisation, Analyse et Commande, Thèse doctoral à l'Ecole Centrale de Lille.

Andoulsi, R., Mami, A., Dauphin-Tanguy, G., \& Annabi, M. (2002). Bond Graph Modeling and Dynamic Study of a Photovoltaic System Using MPPT Buck-Noost Converter, IEEE, International Conference on Systems, Man and Cybernetics, 3.

Benard, V., Cauffriez, L., \& Renaux, D. (2008). The Safe-SADT method for aiding designers to choose and improve dependable architectures for complex automated systems, Reliability Engineering \& System Safety, Elsevier, 9(2),179-196.

Ben Jouida, T. (2008). Contribution à la mise en oeuvre d'une gestion stratégique de la production par l'analyse des postes de travail selon une démarche systémique, étude de cas, Thèse, ENIT, Tunisie.

Ben Salem, J., Lakhoua, M. N., \& El Amraoui, L. (2016). Analysis of a Braking System on the Basis of Structured Analysis Methods, International Journal of Advanced Computer Science and Applications, 7(2). DOI: 10.14569/IJACSA.2016.070212.

Ben Salem, J., Lakhoua, M. N. \& El Amraoui, L. (2017). Approach Based on the Bond Graph Applied to Anti-lock Braking System, Journal Automation \& Systems Engineering, 11(1), 1-10.

Boehinger, A-F. (1968). self-adaptative DC converter for solar spacecraft power supply, IEEE Trans on Aerospace and electronic systems, 4, 102-111.

Cheng, L., Ye, Z., \& Eong, Z. (2016). BG Modeling and Simulation Analysis of Direct Drive Volume Control Electro-hydraulic Servo System With Long Pipeline, International Conference on Aircraft Utility Systems (AUS). IEEE/CSAA.

Demri, A., Lasquo, A. C., Guerin, F., \& Christofol, H. (2008). Functional and dysfunctional analysis of a mechatronic system, Annual Reliability and Maintainability Symposium (RAMS), 114-119. 
Demri, A. (2010). Contribution à l'évaluation de la fiabilité d'un système mécatronique par modélisation fonctionnelle et dysfonctionnelle, Thèse de doctorat.

Diagne, S. (2015). Modélisation sémantique conceptuelle pour l'ingénierie de performances comportementales de produits complexes, thèse de doctorat, Références 151 Université de Strasbourg.

Dumola, D. (2004). User's Manual, getting started with Dumola, Dynamic Modeling Laboratory, and Version 5.3a.

Faucher, J. (2004). Pratique de l'AMDEC, Edition Dunod, Paris.

Flo, A., Kjaernes, M., \& Skomedal, A. (1992). A bridge from structured analysis (SA/RT) to specification and description language, Eighth International Conference on Software Engineering for Telecommunication Systems and Services, 93- 97.

Fritzson, P. (1998). Modelica. A unified object-oriented language for system modeling and simulation, Springer.

Glaa, R., Lakhoua, M. N., \& El Amraoui, L. (2016). Using SA-RT Method for the Analysis and the Supervision of Hydrogen Circuit, Journal of Electrical Engineering, 16(3), 1-6

Jha, M. S., Bressel, M., Ould Bouamama, B., \& Dauphin-Tanguy, G. (2016). Particle filter based hybrid prognostics of proton exchange membrane fuel cell in bond graph framework, Computers \& Chemical Engineering Journal.

Khanh, H. N. (2008). Aide au développement de systèmes temps réel à l'aide d'un langage graphique flots de données, Thèse de doctorat.

Khaouch, Z., Zekraoui, M., Bengourram, J., Kouider, N. \& Mabrouki, M., (2017). Mechatronic Modeling of a 750kW fixed-Speed Wind Energy Conversion System Using the Bond Graph Approach, ISA Transactions.

Lakhoua, M. N. (2009). Application of functional analysis for the design of supervisory systems: Case study of heavy fuel-oil tanks, ITSSA, 5(1), 21-33.

Lakhoua, M. N. (2011). Application of SA-RT method to supervisory systems, Journal of Electrical Engineering, 11(2),44- 45.

Lakhoua, M. N., Ben Hamouda, M., Glaa, R., \& El Amraoui, L. (2016). Structured Analysis and Modeling of a Supervisory Control and Data Acquisition in a Thermal Power Plant, ITEE Journal, 5,1-5.

Lakhoua, M. N., Ben Salem, J., Jabri, I., \& Battikh, T. ( 2020). Application of system modeling and simulation of the photovoltaic production, Int. J. Mechatronics and Automation, 7(2).

Marca, D. (2006). IDEF0 and SADT: A Modeler's Guide, Boston: OpenProcess, Inc., 3rd edition.

Mezghanni, D., Andoulsi, R., Mami, A., \& Dauphin-Tanguy, G., (2007). Bond graph modeling of a photovoltaic system feeding an induction motor-pump, Simulation Modeling Practice and Theory, 15, 1224-1238.

Ould Bouamama, B., \& Thoma, J. (2000). The Bond Graphs, under the direction of Geneviève Dauphin-Tanguy, Thermodynamic and chemical processes, 236-277, IC2 Collection, Hermes Edition, Paris.

Plateaux, R., Choley, J. Y., Penas, O., \& Riviere, A. (2009). Towards an integrated mechatronic design process, IEEE International Conference on Mechatronics,1-6. 
Rekioua, D., \& Aissou, S. (2013). Photovoltaic Panels Characteristics Methodsll, Ceit Tunisa.

Renaux, D. (2013). Specifying systems and applications with SA/SD/RT method, modeling/SA training course 1, IPa10401010-94.

Roboam, X., Astier, S., Foch, H., Fontès, G., Gandanegara, G., Piquet, H., Saisset, R., Sareni, B., \& Turpin, C. (2007). Graphes de liens causaux pour systèmes à énergie renouvelable (partie 2). Techniques de L’ingénieur. D3 971.

Salah, Z., Lakhoua, M. N., \& Sellami, A., (2014). On the Operating Safety and the Analysis of Control-Command Systems, International Conference on Electrical Sciences and Technologies in Maghreb, (CISTEM),1-5.

Schoman, K., \& Ross, D. T. (1977). Structured analysis for requirements definition, IEEE Transaction on Software Engineering 3(1), 6-15.

Turki, S., Soriano, T., \& Sghaier, A. (2005). A SysML profile for mechatronics integrating Bond Graphs, LISMMA Supméca.

Ward, P. T. (1986). The Transformation Schema: An Extension of the Data Flow Diagram to Represent Control and Timing, IEEE Trans. Software Engineering, SE-12(2), 198- 210.

Wertani, H., Ben Salem, J., \& Lakhoua, M. N. (2020). Analysis and supervision of a smart grid system with a systemic tool, The Electricity Journal, 33, 1-8. 